\title{
Untold History of the Interaction Design Institute Ivrea (2000-2005)
}

\section{Elena Formia}

Alma Mater Studiorum

— Università di Bologna

elena.formia@unibo.it

ORCID 0000-0002-6720-0176
Pier Paolo Peruccio

Politecnico di Torino

pierpaolo.peruccio@polito.it

ORCID 0000-0002-0723-6097

\begin{abstract}
Funded in 2000 in Northern Italy, the Interaction Design Institute Ivrea (IDII) was a two-year post-graduate program entirely devoted to educate professionals to tackle a new interpretation of the relationship between human beings, design and digital technologies.

This paper retraces the history and the legacy of this Institution and how it was deeply related to Olivetti's culture, bringing to a wider audience the experimental and visionary educational program through the lenses of some of its main characters: Mr. Franco Debenedetti, IDII Founder and President, Ms. Gillian Crampton Smith, School Director, Ms. Simona Maschi, member of the resident Faculty, and Mr. Giorgio Olivero, student and researcher at that time. The opening in 2021 of the Easy as a Kiss. Vision, story and impact of Interaction Design Institute Ivrea exhibition, curated by Jan-Christoph Zoels, pushed us to explore the origin of the Institution and present a retrospective of the experience.
\end{abstract}

\author{
Keywords \\ Education \\ UX/ID \\ Design history \\ Interaction design \\ Learning by doing
}




\section{Introduction}

The year 2000, the same year of the Millennium bug, was a turning point in the transfer of digital technologies into the consumer arena. Mobile telephony started its rapid growth — in 2000 the Nokia 3310 came out - while the first social networks were about to appear together with the concept of open-source knowledge (Wikipedia was born in 2001). iTunes and the iPod were presented to the market in 2000 and 2001, introducing the logic of digital music sharing. However, in this period, the profession of interaction designer was practically unknown - just think of the first university degrees or associations ${ }^{1}$. Interaction design was mostly conceived as a work to develop computer applications and websites; at the same time, game design was rapidly evolving, pervading this field with interfaces, artistic installations, wearable technologies, Internet of Things, touchscreens, etc.

The Interaction Design Institute of Ivrea (IDII) was founded in 2000 in Ivrea, Northern Italy. It was a centre for graduate education and research entirely dedicated to interaction design, sponsored by Olivetti and Telecom Italia. The Institute gained an international reputation, drawing students, professors and visiting lecturers from all over the world.

A renewed interest in the story of this experience has recently arisen, as it is part of a mosaic of studies about not-conventional education. It also regards the design role played in the computer and digital era, accompanied by the contemporary growth of design thinking methods.

After almost twenty years from IDII's foundation, it is possible not only to read the chronological order of the events that characterized its story, but filter them through the social-economic-cultural context of the time, interpret the legacy of the didactic model and understand the role of the experimental network of people, experiences and projects developed. The possibility to count on direct memories was an opportunity to be seized to get an understanding of the facts. The lack of specific literature on this subject, and the scarcity of available documents, convinced us to adopt an investigation methodology based on questions and answers addressed to key figures of that history. All the responses were contextualized, cross-checked against available resources, and cross-referenced against available data to assess the scope and effects of this institution in the medium and long term.

\section{Design and Politics}

Franco Debenedetti was the founder and President of the IDII, the international post-graduate school launched in 2000 in Ivrea, the city where the typewriter company Olivetti was founded. Debenedetti is an electrical engineer, he was the CEO of Olivetti from 1978 to 1992, and Senator of the Republic for three terms (XII, XIII, XIV). $\mathrm{He}$ is the author of numerous books including Ritagli (2006), Scegliere $i$ vincitori, salvare i perdenti (2016). He writes on /l Sole 24 Ore and // Foglio newspapers. of Art (London), was established in 1990 and the Master of Design Program in Interaction Design, Carnegie Mellon University (USA) in 1994. The Interaction Design Association IxDA was incorporated in 2005. 
Mr. Debenedetti, could you describe your role and the political and social context of that time?

The institution of the IDII is a political, industrial, economic and financial affair, which also intertwines the theme of the privatization of public companies, starting with Telecom. During the period of Romano Prodi's first government ${ }^{2}$, I was intensely involved in the privatization of public companies, and in particular I followed the first privatization of Enel and then Telecom.

In 1995 I was a Senator of the Republic and I followed Olivetti, the company led by my brother $\mathrm{Carlo}^{3}$, from a distance. In that year, Roberto Colaninno was appointed Managing Director of Olivetti, in the darkest period of its history. He announced that he wanted to leave the IT sector and transform the company into a telecommunications holding company: he sold industrial activities at a loss, but without succeeding in reorganizing the overall structure. In 1998, Colaninno sold Omnitel ${ }^{4}$ and Infostrada 5 to Mannesmann. On 20 February, 1999, he launched a 117 billion lire takeover bid for Telecom ${ }^{6}$. He succeeded in conquering the company and began to manage it.

It was a period of close contact with him. One day he told me that he felt indebted to Ivrea, which had allowed the owner of a small filter factory in Mantua to become a businessman with such credit that he was able to launch the largest takeover bid in Italy and one of the largest in Europe. This is the context.

Colaninno created a think tank including myself and entrusted us with the task of designing a "university", as he called it, in Ivrea, to teach human sciences to engineers and, vice versa, technology to humanists.

In my opinion, it didn't make much sense. When, in the evening, I told my wife, Barbara Ghella ${ }^{7}$, about this project, she immediately suggested to shift the focus to interaction design. She is a designer and discovered this "new" topic in 1991, when she met Bill Verplank ${ }^{8}$ in Palo Alto. It took her a while, but she convinced me that this was the right thing to propose to Colaninno.

Immediately after, we left for San Francisco to meet David Kelley ${ }^{9}$, Bill Verplank and many other experts in interaction design. We also came into contact with the name of Gillian Crampton Smith, professor at the Royal College of Art in London, to convince her to take part in this adventure. We returned from that trip with the project.

Colaninno approved it and, in February 2000, the Telecom Board of Directors gave the go-ahead to establish a post-university school of interaction design in Ivrea. On 16 June, 2000, the Interaction Design Institute Ivrea association was founded, with an endowment of 39 million euros for the 2000-2005 period.

By June 2000 we brought on board Gillian, Director and key person of the initiative.

\section{2}

From May 1996

to October 1998.

3

Carlo Debenedetti was

President of Olivetti from 1978 to 1996.

4

Omnitel was founded in 1994 from an entrepreneurial idea of Carlo

Debenedetti and Elserino Piol. On 29 March 1995 Omnitel won the tender for the second mobile telephone operator.

\section{5}

Infostrada was born in 1996 from an agreement between Olivetti and Bell Atlantic with the aim of competing with Telecom Italia in the fi ed telephony sector.

\section{6}

The historical Italian telecommunications society was born in the Fascist period. In the 1960s it was transformed into SIP (Società Italiana per I'Esercizio Telefonico), then finally elecom Italia in 1994.

$$
7
$$

Head of Projects and Collaborations of IIDI. Member of the Steering Committee and of the Coordination Committee, with Gillian Crampton Smith (head of Graduate School) and Sebastiano Bagnara (head of Knowledge Exchange). She studied architecture at the Politecnico di Torino, design at the Scuola Politecnica di Design Milano, and medicine at the Università di Torino.

$$
8
$$

Interaction designer, human factors engineer and Visiting Scholar at Stanford University. He served on the Steering Committee for the IDII together with, among others, Gillian Crampton Smith, John Thackara, Marco Zanini, Bill Moggridge. 
The teaching program, the project for the renovation of the building, the statute, and the business plan for five years were all designed and approved.

The building was inaugurated in December 2000; research activity began in January 2001; and the first group of students arrived in September.

I drew up a statute that would allow us to work for five years without having to ask for refinancing every year, and I made sure to protect the governance from interference or outside interests: i.e. the School had to be autonomous and not a tool in the hands of its shareholder, that is the founder Telecom.

Why did the School close in $2005 ?$

Unfortunately, industrial and financial events drove, for the second time, the fortunes of the IDII. Marco Tronchetti Provera $^{10}$, head of Pirelli, took control of Olivetti-Telecom in July 2001. The imperative at the time was to reduce Telecom's debts... and Pirelli was already involved in a prestigious design school in Milano: the Domus Academy. Therefore, they decided to merge the two institutions.

I fought to oppose this choice, and when I saw that it was not possible, I resigned.

I knew it would fail.

The last people walked out of the IDII building in Ivrea in December 2005.
9

Founder and President of IDEO Product Development and Professor of Industrial Design at Stanford University. He was member of the Explorers Club of the IDII.

10

He entered in Pirelli in 1986 and took over the operational leadership of the Group in 1992. He was chairman of Telecom Italia from 2001 to 2006.

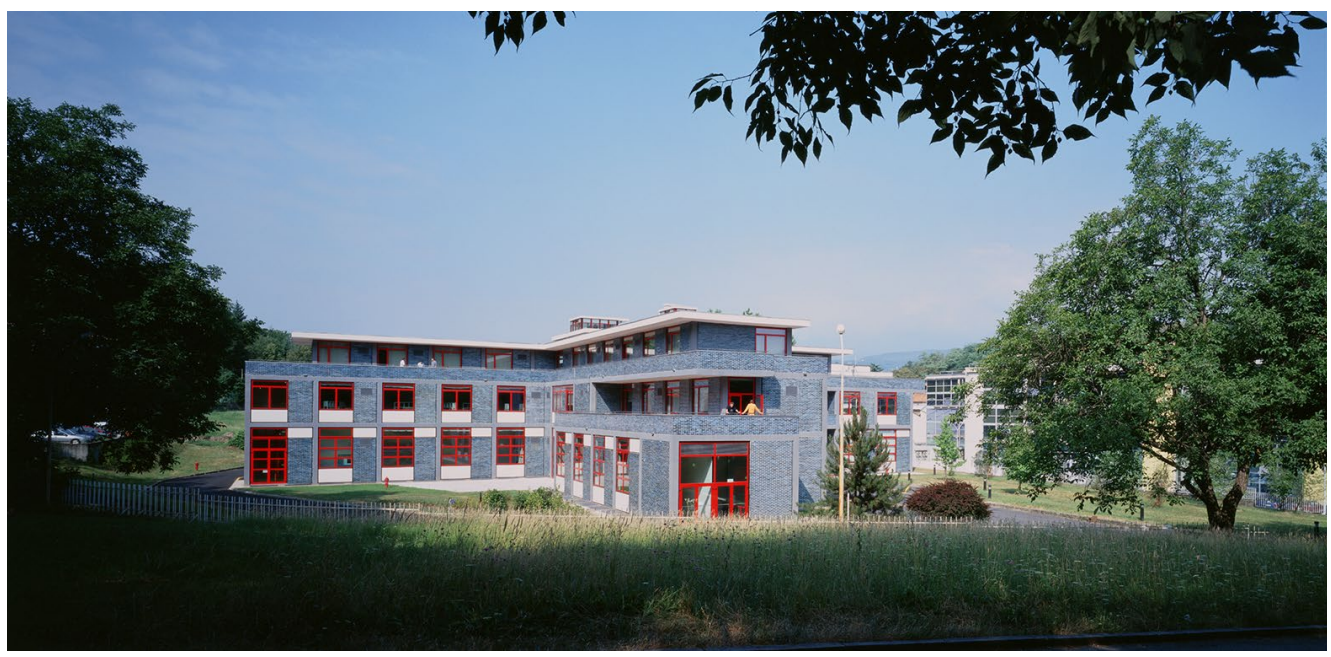

\section{From Typography to Interaction Design}

Gillian Crampton Smith was Professor and Head of the Computer Related Design Department (CRD) at the Royal College of Art, London, when she moved to Ivrea to direct the IDII. From 2006 to 2014 , with Philip Tabor, Director of the Bartlett School of Architecture, she was the Head of the Interaction Design at IUAV University, Venice.
The Blue House, Interaction Design Institute, Ivrea. (C) Santi Caleca. 
Ms. Crampton Smith, which teaching models were you looking at? At Ivrea I intended to continue our successful Computer Related Design (CRD) teaching model developed at Royal College of Art (RCA), which, like all British art and design schools, was rooted in the Arts and Crafts tradition, starting with William Morris, married to the German Bauhaus. The British design teaching model, as one might expect from such a pragmatic country, is learning by doing. The curriculum is project-based, but not projects that mimic real life, but rather projects that develop students' imaginations, train them to think out of the box, to entertain the outrageous, because in the space between the normal and the outrageous they will find solutions that are both innovative and feasible, technically and culturally. In this, the model is closer to art than to engineering.

I came to interaction design from graphic design and typography. Designing a layout application in the 1980s, I realised that the everyday skills and knowledge of graphic designers could make software not only more beautiful but easier to use.

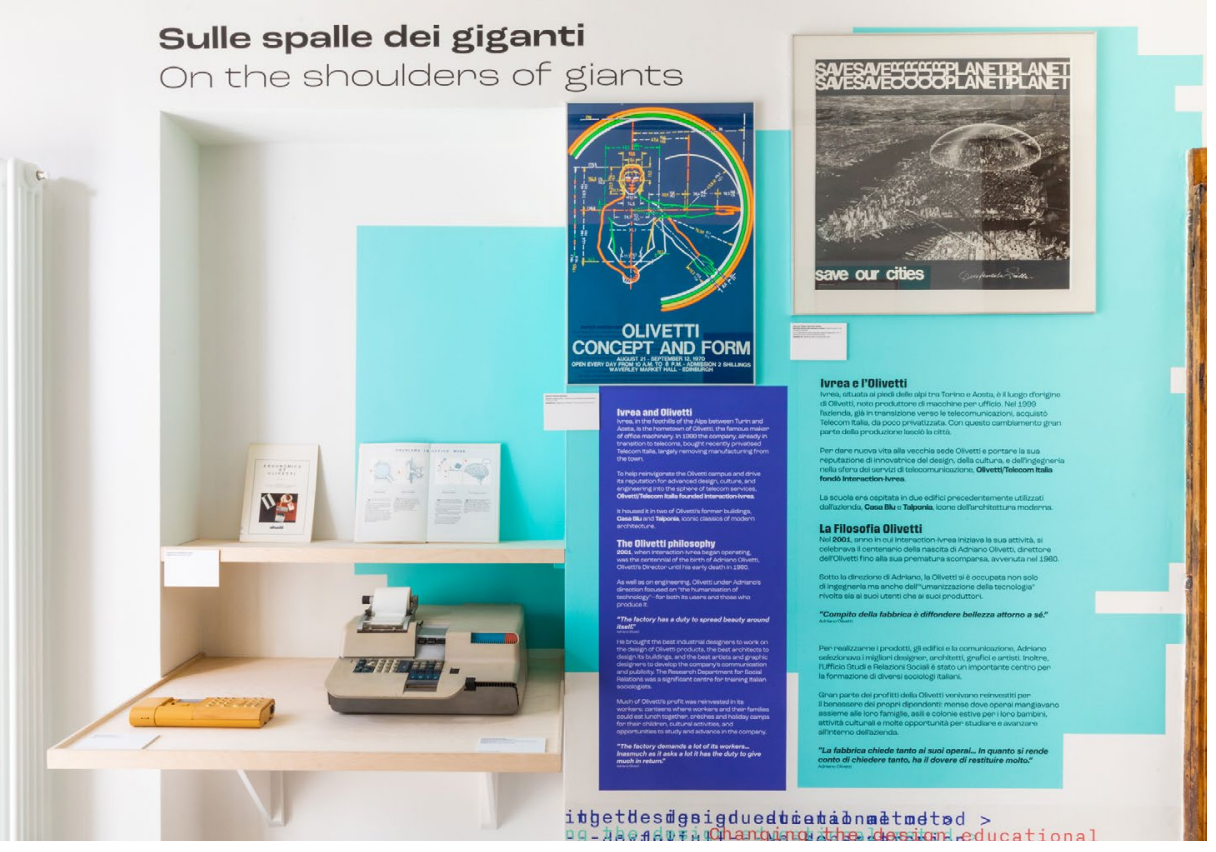

So, this was one of the fundamental tenets of our teaching: design is not just making things pretty, it is also about making them work better. Second, was the belief that if designers understood properly how digital technologies work, as they do with the other materials they work with - plastics, print, fabrics, concrete - they would be able to imagine new ways of using the digital material. Thirdly, design is also about giving meaning to people's lives: digital technologies need to have the same cultural richness we expect from the

The room devoted to Olivetti's legacy of the exhibition Easy as a Kiss. Humanizing technology through design. Vision, story and impact of Interaction Design Institute Ivrea, curated by Jan-Christoph Zoels, Circolo del Design (Turin), 2021. (c) Circolo del Design, ph. Cosimo Maffion 
other arts - film making, architecture, products in our home, our clothes.

In 1990 I attended my first $\mathrm{CHI}$ (Computer Human Interface) conference in Seattle and I noticed the exclusive participation of psychologists or computer scientists, interested in what was then called $\mathrm{HCl}$ (Human Computer Interaction). So, this was the fourth part of the teaching model: collaboration with companies - both sides could learn from one another.

The CRD Department at the RCA was both a teaching programme and a design research studio, funded by tech companies. We wanted to copy this at Ivrea but also to add diffusion of knowledge about what interaction design is and why it is important. So there were three legs of the Institute: Education; Research and Collaboration with industry; and Knowledge Sharing.

How did the School work?

Our first hire was the Director of Administration: an ex-OIivetti engineer whose work on the Institute's infrastructure enabled students and Faculty to flourish. At the beginning of 2001 we started to choose the professors, helped by Wert\&Co. of New York, one of the few interaction design head hunters that existed then. We were aiming for a range of disciplines: primarily interaction design, graphic design, product design, computer science, service design, as well as a mix of Italians and other nationalities. The first professors were from Austria, Germany, Italy, Norway and the USA.

The next phase was to invite six designers and artists in residence for a three months project in Ivrea to test out all our systems before the students arrived and to have some projects to show when we started the academic year.

We started then to advertise and interview potential students. In the first year, tuition and lodging (in Talponia ${ }^{11}$ ) was free. We realised that to start something from zero, in a place few people outside Italy know about, in a subject hardly anyone had heard of, we needed to make it as easy as possible for people to apply.

As well as our Steering Committee we had a group of about twenty Explorers, leading people in the Human Computer Interaction field from Europe, USA, Asia and India who wanted to help us ${ }^{12}$. Potential students learnt about the Institute through this network and through my contacts in the $\mathrm{CHI}$ community.

We sifted the applications and interviewed by telephone about fifty candidates for the twenty-five places. We aimed for a diverse group of men and women with different disciplines and from different countries. The majority were designers but also psychologists, business people, computer scientists among others. Many of our students were American because, though the USA led the world in IT and interaction design, at that time there were hardly any USA teaching programmes - Carnegie Mellon University was an exception. Our first cohort came from Denmark, England, India, 
Israel, Italy, Japan, Serbia, Sweden, Turkmenistan, the USA and Venezuela. We were disappointed not to attract more Italian students. An Italian degree programme was typically five years long, so many potential students could not face another two years of study, particularly in a city reputed to be less than lively. In addition, the career opportunities offered by interaction design were poorly understood in Italy.

The course was two years long: the first year was taught lecture, studio classes and the second year an individual thesis project. This programme was punctuated each term by Applied Dreams two-week rapid projects in conjunction with a company, which would also send some of their junior designers to take part.

The taught programme was project-based and covered three areas: screen-based computer applications, physical computing, and service design, with a fourth slot for some unforeseen interesting opportunity - like the Salone del Mobile exhibition we put on at the Milan Triennale, for instance. In the first term the designers learned basic programming and non-designers basic graphic information design applied to screen design. The residence, Talponia, allowed us to host visiting designers and bring many interesting people to do workshops and lectures, both enriching the community and helping it become known and attract talented applicants.

\section{Prototyping Experiences}

Simona Maschi is co-founder and Director of the Copenhagen Institute of Interaction Design (Denmark/Costa Rica). She graduated in Architecture from Politecnico di Milano in 1995, with a thesis on product design supervised by Ezio Manzini. She spent a period of internship at Material ConneXion, New York City. Later, she worked as a researcher at Politecnico di Milano in the field of service design and sustainability. These issues became the subject of her Ph.D. thesis on design of future scenarios. In those years, she worked on storytelling as a tool to materialize hypotheses of possible futures, and on understanding scenarios as a way to envision new behaviours, thanks to the development of digital technologies. She was a visiting scholar at the Institute of Design (IIlinois Institute of Technology), where she collaborated, among the others, with Victor Margolin and John Heskett.

Ms. Maschi, how did the relationship with the IDII start and which was your role there?

I arrived in Ivrea at the end of the first year and stayed until the School closed. I will never forget the first day I arrived from Chicago for the interview, in 2000. Everyone was there: Gillian Crampton Smith, Bill Moggridge, John Maeda, Bill Verplank, John Thackara.

I was in charge of two modules in the first year: Video Sketching (a two-week long module) and Service Design (a four-week long module). The first was related to my Ph.D. thesis; to the idea of using video as a tool to sketch with. We usually sketch with a pencil, to start shaping something, where errors and 
inaccuracy are admitted. I wanted to bring that approach to the video tool, so that we could express stories instead of products.

The second course in the field of Service Design was called Zoom In-Zoom Out because of the service designer's ability to design both the touch point (the actual point of interaction between people and a screen or a tangible artefact), as well as the overall flow of an interaction or a service.

I was also in charge of creating projects in collaboration with companies to transfer the processes, tools, and know-how we taught to the students outside the school. For example, I worked with Telecom Italia in Rome and with Fiat in Turin, for which we developed a pioneering car-sharing service: Multiplas. It was developed on the occasion of the 2006 Turin Olympic Winter Games. We worked in collaboration with Roberto Giolito, the designer of the Multipla, by the design department at FIAT. The 360 Degrees project, on the other hand, was a concept car in which we imagined new behaviours through the use of connected screens instead of the traditional dashboards.

The teaching staff was composed of few resident members (such as Massimo Banzi ${ }^{13}$, Jan Christoph Zoels ${ }^{14}$, another five or six professors, and myself); while most of the Faculty members came from outside to teach their courses during short periods. We assisted students and nurtured the innovation process through the legacy of Olivetti.

At the centre of the didactic area there were digital technologies, in their boom years. In these years Processing - integrated development environment (IDE) and programming language - was born, as was Arduino ${ }^{15}$. There, we could experiment with technologies, but also, and above all, we could work on why to use them: we could demystify their power as drivers of innovation, making them accessible to everyone, crafting them very quickly, with informal processes, with living lab dynamics and co-creation. The school showed that you can prototype quickly and without special engineering skills, and - while doing so - prototyping became a process to empower creativity rather than constraining it.

I will never forget a beautiful statement by Bill Moggridge during the students' review regarding the importance of prototyping: “You can't experience an experience without experiencing it".

What is the contribution of the IDII in terms of new educational methodologies?

Ivrea has left an incredible legacy for future education in the design field.

I believe we can identify three fundamental contributions.

The first concerns the cultural transition from product to experience design, driven by the rise of digital technologies. The second is cross-disciplinarity. Gillian Crampton Smith oversaw the selection of first year students, where everyone brought a different contribution: from psychology, economy, technology, to design - including fashion, graphic, and prod-
Co-founder of the Arduino project. He is an interaction designer, educator and open source hardware advocate. He taught at the IDII for four years.

14

Founding partner of Experientia, where he is in charge of user experience design. He taught at the IDII. He co-curated the events Humanizing technology through design, Turin, Circolo del Design, 2021.

\section{5}

An open-source electronics platform developed at the IDII to allow non-engineering students to easily prototype physical devices controlled by computers. 
uct designers. The result was to have people with different backgrounds working together to create new experiences. They were required not only to design the form-function, but the whole behavioural aspect of the concept. In this sense, prototyping became their common language. Finally, many of us - both faculty and students - have been ambassadors of this kind of teaching and pedagogy in Europe, USA, South America, and the Middle and Far East.

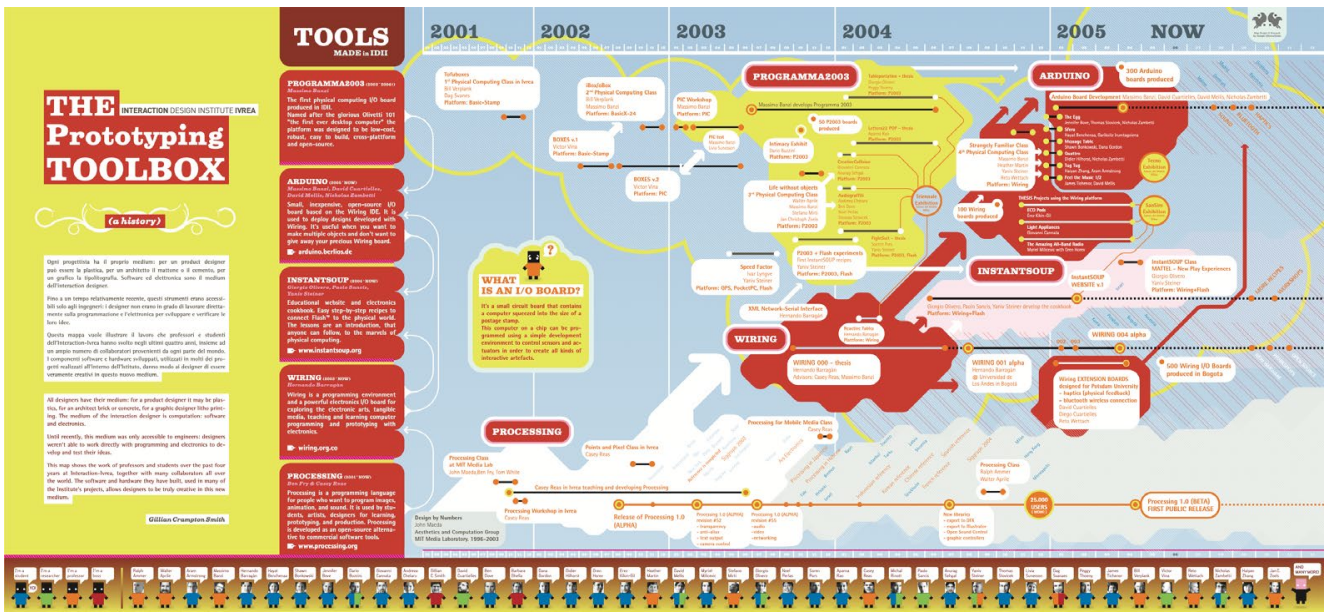

\section{Beyond Interaction}

Giorgio Olivero is a designer of interactions, a maker of new products and an innovation strategist. After graduation, he was hired by the IDII to develop concepts for the InstantSOUP project, a website and a series of workshops to teach electronic prototyping in a playful, non-technical way.

In the last year, there have been several occasions to celebrate the IDII (from the conference on the occasion of the Biennale Tecnologia of the Politecnico di Torino at the end of 2020, up to the exhibition Easy as a Kiss, with related events linked to the theme Humanizing technology through design). Beyond the virtuous elements that have distinguished this episode, according to your opinion, is it possible to find some criticalities?

Your interest regarding the critical issues, if any, of what you define as "the IDII episode" doesn't come as a surprise though, it is quite relatable in fact. While the IDII's achievements have been widely recognized, there are few critical voices against its weaknesses. The IDII did not hide its ambition to become a part of the "great modern design" lineage. It branded itself as a "digital Bauhaus" from the very start, the logo was a tribute (or a refresh) of the Bauhaus one designed by Oskar Schlemmer in 1921, the institute's blue building was dubbed "bluhaus". The school did pass us some kind of highly effective "secret sauce", even if the recipe now looks deceitfully simple compared to how fresh it felt
Giorgio Olivero, Map of the work of the professors and students that contributed to the creation of designer-friendly software and hardware tools during Interaction-Ivrea's lifetime, 2006. (c) Giorgio Olivero. 
in the early 2000s: engage with your users to understand their experiences and needs, come up with new design opportunities, add a hefty dose of just-enough prototyping, test it out with real people, rinse and repeat until it tastes great. Thanks to a talented, eccentric and diverse community of students and Faculty that freely bounced ideas around, the recipe continued to evolve and develop. Upon graduation, the students were able to run with it. The institute had such a short lifespan because Telecom Italia's initial five-year endowment ran out and it wasn't renewed by the new, mildly myopic owners who, in 2005, the year YouTube was founded, still couldn't see the business value of designers learning to play with technology. I think part of the IDII-myth owes to the fact that we all shared the enthusiasm of the explorers, the thrill of setting foot in a new land, akin to the discovery of a new sort of computational magic. As a community, we also shared a few blind spots for what was coming our way. What are the consequences of a design concerned on how to shape human behaviour? What happens when interactions become data-producing events and are used to precisely predict actions, reactions, inclinations, emotions, behaviours? Even the title of the events you mentioned, Humanizing technology through design, evokes its mirror image "dehumanising people". What happens when a design discipline creates a system of dependency by giving people what they "want" without too much concern for the consequences? We - the students, the School, as well as the profession in its infancy, did not examine the discipline's potential consequences with a more critical eye.

\section{Could you tell us a project you did there that could be still actual} today?

This is a design brief I got from Gillian Crampton Smith after I graduated. She asked me to research and design a map of the work of the professors and students that contributed to the creation of designer-friendly software and hardware tools during Interaction-Ivrea's lifetime. These tools were quite revolutionary, as hard-to-use technologies were finally being made accessible to non-engineers. She wanted to capture and illustrate the four-year momentum that led to prototyping frameworks such as Wiring ${ }^{16}$ and Arduino. As it is often the case with historical records, this map eventually became controversial and was criticized by my genius classmate Hernando Barragán in his very detailed article The Untold History of Arduino ${ }^{17}$. This brings us back to your initial question regarding the visibility of critical voices and critical issues. Hernando's document offers a fascinating example of a counter narrative that has received little attention. I don't really possess the information or the detailed knowledge to validate or refute Hernando's claims, but it's a great read if you enjoy playing design-detective and if you are curious about the origins of some of the most widely used electronic prototyping tools.
It is an open-source programming framework for microcontrollers.

\section{7}

https://arduinohistory. github.io/

\section{Elena Formia}

Ph.D., Associate Professor of Design at the Department of Architecture of the Alma Mater Studiorum Università di Bologna, where she is Director of the First Cycle Degree in Industrial Design and the Second Cycle Degree in Advanced Design.

\section{Pier Paolo Peruccio}

Ph.D., Associate Professor of Design at the Politecnico di Torino and Visiting Professor at ECAM/University of Lyon, France. He is a Board Member of the World Design Organization (WDO) and the Italian Design Society (SID). He teaches Design History in the BSc; Theory and History of Systemic Design in the MSc and Design Studies in the Ph.D. program. 